\title{
Calling All Social Workers: Step Up, Give Voice, and Educate
}

\author{
Shirley Gatenio Gabel ${ }^{1}$ S Susan C. Mapp ${ }^{2}$
}

Published online: 19 August 2021

๑) The Author(s), under exclusive licence to Springer Nature Switzerland AG 2021

As social, economic, and political issues progressively become more global, so too are the responses to these issues, and the responses are increasingly addressed through a rights-based, collective perspective. Regardless of practice methods, social workers train to help address the needs of people and work toward establishing a more just society. International social work organizations agree that a rights-based approach to social work practice is needed for social workers to facilitate a just society. IFSW and IASSW affirmed that the "principles of human rights and social justice are fundamental to social work" in their International Definition of Social Work (IFSW\& IASSW, 2004, p.1).

Despite this, not all social workers are trained in human rights-based approaches. If we genuinely want to transform our societies into equitable, free, and caring communities, we must train social workers to practice from rights-based approaches that value the process as much as the outcome. The UN declarations, conventions, and treaties provide a human rights framework. To turn this framework into reality, social workers and social work educators must train current and future social workers in rights-based practices so that social work practices and social policies can facilitate the realization of rights.

The cost of not training social workers to practice from human rights perspectives is perpetuating societal political, social, economic, and civil inequities that further marginalize and exclude people worldwide (Reynaert et al., 2019). Training all social workers to practice from a rights-based approach re-unites a profession that was increasingly dichotomized into clinical and macro approaches over time (Mapp et al., 2019). Bringing a rights-based approach to

Shirley Gatenio Gabel

gateniogabe@fordham.edu

Susan B. Mapp

mapps@etown.edu

1 Fordham University, Bronx, NY 10458, USA

2 Elizabethtown College, 1 Alpha Dr, Elizabethtown, PA 17022, USA social work practice also presents an alternative approach to caring for one another than offered by neo-liberalism. As Reynaert et al. has noted, "Social work is neither a valueneutral practice nor a practice devoid of power in addressing issues of injustice and inequality" $(2019$, p. 2). The power of the human rights approach is to reconnect all social workers to advocacy at local, regional, national, and global levels. The approach emphasizes the person-in-environment framework that is fundamental to social work practice.

And yet, as recent studies have noted, many social work programs are unclear around their goals for human rights education, emphasize knowledge of instruments rather than practice application, and are dependent on the knowledge levels of faculty members who in many cases have limited training on social work education (Chen et al., 2015; Chiarelli-Helminiak et al., 2018; Gatenio Gabel \& Mapp, 2019; Richards-Desai et al., 2018).

The first few articles in this issue contemplate the challenges of human rights education. Becker, from South Africa, focuses on the need for, and how to teach and learn, action and activism towards realizing human dignity in preservice and in-service social work programs from the positioning of a protest school. Also writing from South Africa are Nomngcoyiya and Kang'ethe, on the difference human rights education in social work practice can make on traditional male circumcision and furthering men's educational advancement. Benson and Siciliano move us to Tunisia and show us how a course tied to fieldwork with a Tunisia-based migrant-led organization that advocates for missing migrants who have gone missing can teach social work students about how to apply human rights from theory to practice. Akilova would agree as in her article; we learn that experiential rights-based education provides essential skills necessary for social workers in humanitarian practice with displaced persons.

As history has repeatedly shown us, those who have been marginalized, hold and have access to fewer resources, and live in societies that do not recognize the universality of human rights, are most likely to suffer during times of crisis. The COVID-19 pandemic has proven this to be true, 
once again. Tirivangasi et al. help us understand how the catastrophic implications created by climate change on rural women are magnified in several areas by the COVID-19 pandemic (food security, livelihood strategies, accentuated caregiving roles, and access to healthcare systems) and are reinforcing gender inequalities, social exclusion, and patriarchal dominance. Choolayil and Putran investigate the concept of human dignity of migrant laborers in India within a welfare state during the pandemic context. The complicated dynamics of xenophobia and violence against Asian Americans within the intersections of science, religion, and cultural diversities are explored by Choi and Lee in this issue. Wang et al. look at the differences between people in Canada and the USA on leadership, reliable information, and coping during the pandemic.

In all, the articles in this issue point to the need for social workers to step up advocacy roles and provide accurate information, particularly in crises, when those on the margins of society are most likely to suffer more than others in society.

\section{References}

Chen, H. Y., Tung, Y. T., \& Tang, I. C. (2015). Teaching about human rights in a social work undergraduate curriculum: The Taiwan experience. British Journal of Social Work, 45(8), 2335-2350. https://doi.org/10.1093/bjsw/bcu068

Chiarelli-Helminiak, C. M., Eggers, M., \& Libal, K. R. (2018). The integration of human rights in US social work education: Insights from a qualitative study. Journal of Human Rights and Social Work, 3, 99-107. https://doi.org/10.1007/s41134-018-0050-y

Gatenio Gabel, S., \& Mapp, S. C. (2019). Teaching human rights and social justice in social work education. Journal of Social Work Education, 56(3), 428-441. https://doi.org/10.1080/10437797. 2019.1656581

International Federation of Social Workers \& International Association of Schools of Social Work. (2004). Retrieved from https://www. iassw-aiets.org/wp-content/uploads/2015/10/Ethics-in-SocialWork-Statement-IFSW-IASSW-2004.pdf

Mapp, S., McPherson, J., Androff, D., \& Gatenio Gabel, S. (2019). Social work is a human rights profession. Social Work, 64(3), 259-269. https://doi.org/10.1093/sw/swz023

Reynaert, D., Dijkstra, P., Knevel, J., Hartman, J., Tirions, M., \& Geraghty, C. (2019). Human rights at the heart of the social work curriculum. Social Work Education, 38(1), 21-33. https://doi.org/10. 1080/02615479.2018.1554033

Richards-Desai, S., Critelli, F., Logan-Greene, P., Borngraber, E., \& Heagle, E. (2018). Creating a human rights culture in a master's in social work program. Journal of Human Rights and Social Work, 3, 169-178. https://doi.org/10.1007/s41134-018-0059-2

Publisher's Note Springer Nature remains neutral with regard to jurisdictional claims in published maps and institutional affiliations. 